\title{
St. Augustinegrass - Made for the Florida Shade? ${ }^{1}$
}

\section{L.E. Trenholm and Russell Nagata ${ }^{2}$}

\section{Introduction}

Landscapes generally contain areas where turfgrass will grow under some degree of shade for some part of the day. Turf will often decline over time in heavier shade, which may not allow full sunlight throughout the day. Turf in these areas is expected to perform comparably to grass growing in full sunlight, and is generally maintained under the same fertility and cultural regimes as grass in full sunlight. While St. Augustinegrass (Stenotaphrum secundatum [Walt.] Kuntze) cultivars are typically recognized as having better shade tolerance than other turf species used in Florida, cultivars do vary considerably in their shade tolerance. Typically, they possess relatively good tolerance to shade; however, there is significant variation within the St.

Augustinegrass species for shade tolerance.

Although reduced light levels are one problem encountered in shaded environments, there are other factors that negatively influence turf growth. These include:

- Altered light quality under tree shade due to use of "photosynthetically active radiation" by the tree. The tree absorbs the light needed for photosynthesis before it can ever reach the grass. This changes the way the grass grows in response to the light it receives.
- Competition with tree roots for soil, air, water, nutrients, and space.

- Reduced air movement, which can encourage disease growth.

- Potential for increased transplant shock - these grasses were undoubtedly grown in a sunny sod field and now have to acclimate to different environmental conditions following harvest and transplant.

\section{Cultivar Trial}

Due to a lack of qualitative information regarding how much shade St. Augustinegrass can actually tolerate before turf quality and vigor declines and about how new cultivars may compare with older cultivars for shade tolerance, a 14-month glasshouse trial was conducted to evaluate shade tolerance of St. Augustinegrass cultivars.

Five St. Augustinegrass cultivars (Bitterblue, Floratam, Palmetto, Seville, and 1997-6, an experimental line) were subjected to 4 different light regimes $(0,30,50$, and $70 \%$ shade). Grasses were grown in 6-inch pots placed under PVC-frame shade structures fitted with shade cloth to provide 30,50 , or $70 \%$ shade (Figure 1). Evaluations were made over

1. This document is Fact Sheet ENH967, one of a series of the Environmental Horticulture department, Institute of Food and Agricultural Sciences, University of Florida. Publication date: October 8, 2003. Please visit the EDIS website at http://edis.ifas.ufl.edu

2. L.E. Trenholm, Assistant Professor, Extension Turfgrass Specialist, Environmental Horticulture Department, Institute of Food and Agricultural Sciences, University of Florida, Gainesville, FL.; Russell Nagata, Associate Professor, Horticultural Sciences Department, Everglades REC, Belle Glade, FL.

The Institute of Food and Agricultural Sciences (IFAS) is an Equal Employment Opportunity - Affirmative Action Employer authorized to provide research, educational information and other services only to individuals and institutions that function without regard to race, creed, color, religion, age, disability, sex, sexual orientation, marital status, national origin, political opinions or affiliations. For information on obtaining other extension publications, contact your county Cooperative Extension Service office. Florida Cooperative Extension Service / Institute of Food and Agricultural Sciences / University of Florida / Larry R. Arrington, Interim Dean 
two 7-month periods for physiological and morphological responses to light levels. Measured responses included visual quality, color, and density of grasses, shoot and root growth, leaf chlorophyll concentration, leaf morphology (length and width of leaf blades), leaf area index, concentration of stored carbohydrates, and photosynthetic activity.

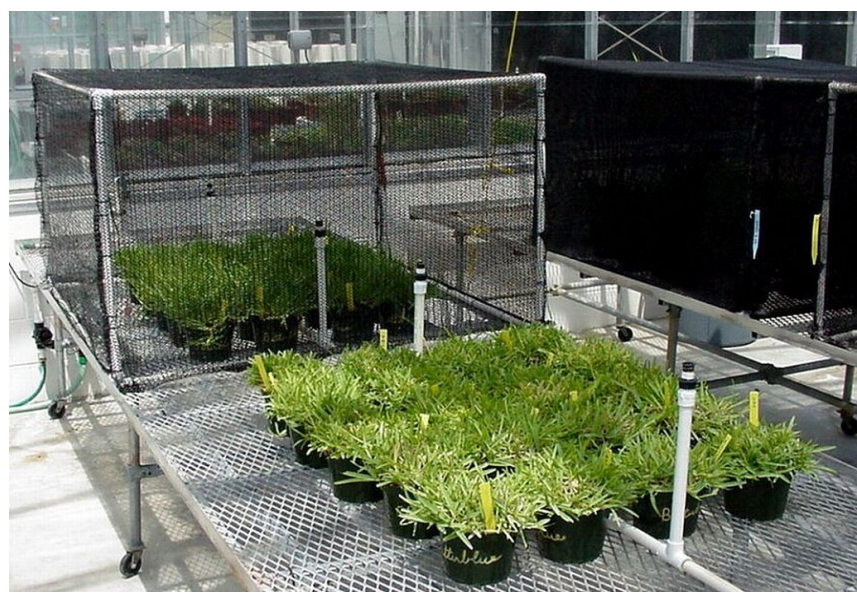

Figure 1. Experimental units in the Envirotron greenhouse. Foreground are full sun treatments, left rear is $30 \%$ shade treatment. Right rear is $70 \%$ shade treatment.

\section{Results}

Quality scores differed significantly between cultivars at different shade levels when averaged over the trial period (Figure 2). At 30\% and 50\% shade, Seville and 1996-7 both ranked in the highest statistical category for quality. At $70 \%$ shade, all cultivars had significantly reduced quality, with lowest quality in Floratam. Using a ranking of 6 as minimally acceptable turf quality, Floratam quality fell below acceptable levels at 52\% shade, Palmetto and 1997-6 at 64 and 65\%, respectively, while Seville and Bitterblue maintained quality at acceptable levels up to $70 \%$ shade.

Maximum quality levels were reached at slightly different shade levels, ranging from $16 \%$ shade for Palmetto to $22 \%$ shade for Floratam. Quality ratings then declined as shade increased from these levels. Most turfgrasses are well adapted to low levels of shade, which is logical when you consider that the plant is subjected to less heat and drought stress than if it were growing in full sunlight.

Color scores also differed between grasses at all shade levels except for 50\% (Figure 3). Seville

\section{Average Quality Scores}

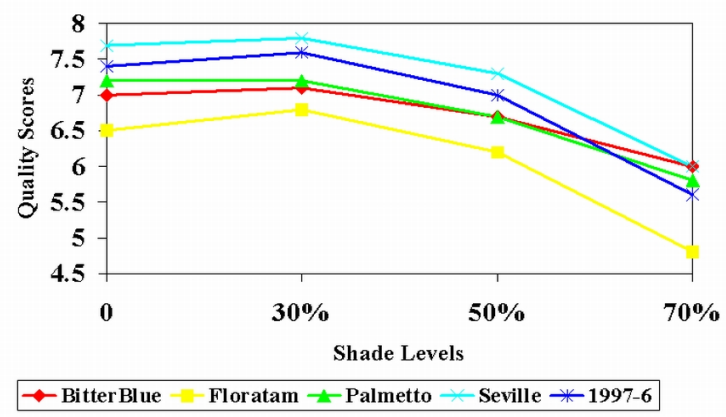

Figure 2. Average quality scores of different St.

Augustinegrass cultivars at increasing shade levels. A score of 6 is considered minimally acceptable.

ranked in the highest group at each light level, while Bitterblue was in the highest group at $70 \%$ shade only. All cultivars maintained acceptable color rankings through $70 \%$ shade. This is not surprising if you consider that concentration of chlorophyll increases as shade levels increase. Chlorophyll is the pigment that reflects green light in leaf blades, and its presence contributes significantly to determine how green a leaf blade appears. We would therefore expect to see dark green leaf blades at the higher shade levels, as long as the plant was able to continue photosynthesizing.

\section{Average Color Scores}

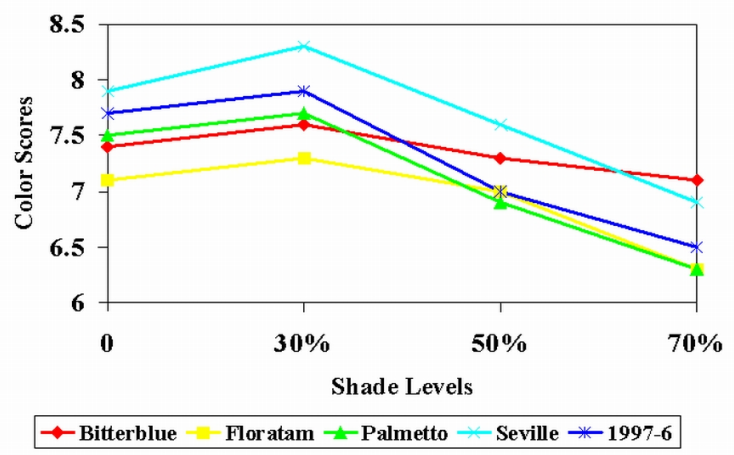

Figure 3. Average color scores of different St. Augustinegrass cultivars at increasing shade levels. A score of 6 is considered minimally acceptable.

Density scores differed between grasses as well (Figure 4). Seville was consistently in the highest ranking and Floratam in the lowest. At $70 \%$ shade, Palmetto and Bitterblue were also in the highest ranked group. Unacceptable density occurred at 58\% shade for Floratam and 69\% shade for 1997-6, while 
the other cultivars maintained acceptable levels through $70 \%$ shade.

\section{Average Density Scores}

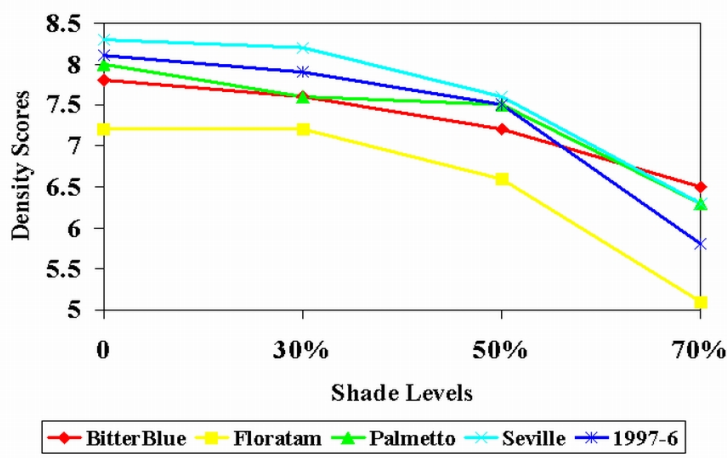

Figure 4. Average density scores of different St.

Augustinegrass cultivars at increasing shade levels. A score of 6 is considered minimally acceptable.

Maximum density scores were generally reached at low shade levels, ranging from $5 \%$ for Bitterblue to $19 \%$ for Floratam. You would expect that density ratings would decrease more as shade increases, which is what is seen in shoot count and growth data at the higher shade levels.

A final harvest after seven months of shade treatments revealed many differences between grasses. Under 70\% shade, Seville and 1997-6 produced the highest number of shoots per pot (Figure 5).

Shoot Counts at Terminal Harvest

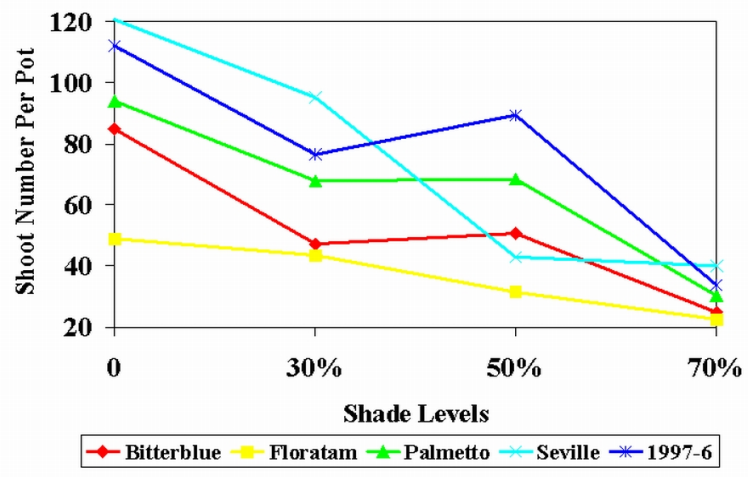

Figure 5. Number of shoots per pot after 7 months of shade treatments.

Actual weight of shoot growth per pot at $70 \%$ shade was greatest in Seville, Bitterblue, and Floratam (Figure 6). This measurement is affected by leaf width and leaf length of the cultivars, with Floratam and Bitterblue having wider leaves than many other cultivars.

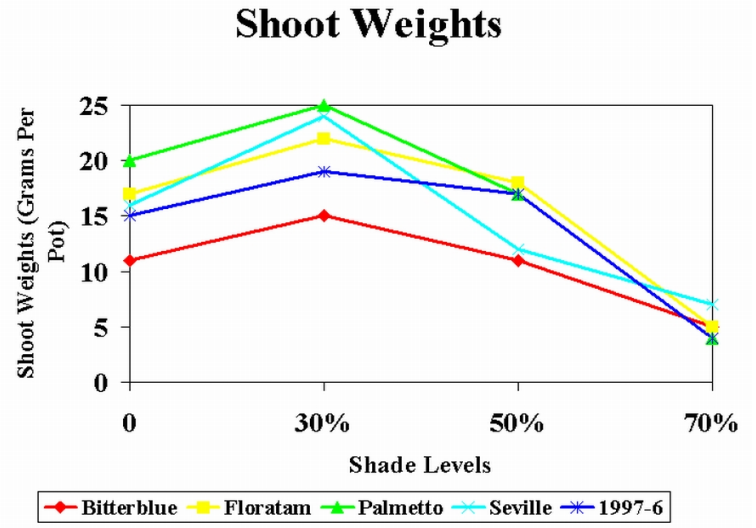

Figure 6. Shoot weights per pot after 6 months of treatments.

Leaves grow significantly longer under shade (Figure 7), which contributes to higher leaf weights. It is interesting that at $70 \%$ shade, Seville, which is considered a dwarf cultivar with shorter, thinner leaf blades, produced as much shoot tissue as the larger cultivars. This directly relates to the ability of Seville to maintain good density under heavy shade. The ability to produce ample shoot growth means the grass has the ability to maintain shoot density and therefore the ability to maximize photosynthesis under reduced light.

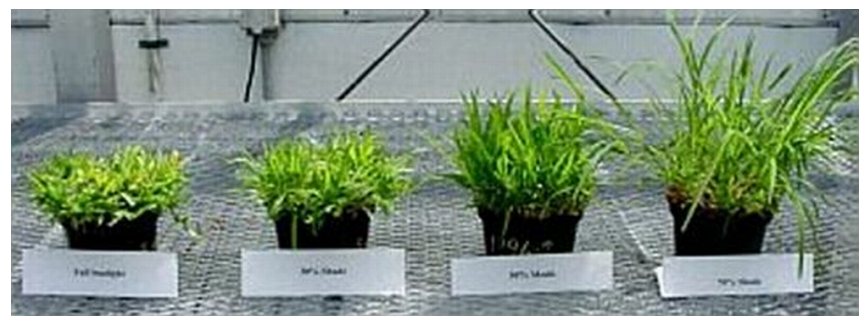

Figure 7. Grasses after 3 months of treatments. From left to right: $0,30,50,70 \%$ shade.

Other measurements are still being analyzed and will contribute to our conclusions on shade tolerance of St. Augustinegrass. The data analyzed to date, however, indicate that Seville and 1996-7 have better overall shade tolerance at up to $50 \%$ shade. This is typical of dwarf St. Augustinegrass cultivars, which are generally seen as having greater shade tolerance. At higher shade levels, all of the cultivars have reduced quality levels, with Floratam being significantly lower in quality than the other cultivars. 
All of the cultivars were able to handle shade of approximately $50 \%$ based on results of this study, although Floratam would experience substantial thinning over time at this level of shade. 